\title{
Gingival Lipoma: A Rare Case Report
}

\author{
Dr. Sweta Shrestha, ${ }^{1}$ Dr. Shaili Pradhan,${ }^{2}$ Dr. Ranjita Shrestha Gorkhali ${ }^{3}$ \\ ${ }^{1}$ Resident, ${ }^{2}$ Professor, ${ }^{3}$ Asst. Professor, Periodontology and Oral Implantology Unit, \\ Department of Dental Surgery, National Academy of Medical Sciences, Bir Hospital, Kathmandu, Nepal
}

\begin{abstract}
Lipomas are benign tumours of mesenchymal origin (mature adipocytes) that are comparatively uncommon in the oral cavity corresponding to less than $4.4 \%$ of all benign oral soft tissue tumors. Clinically, they present as slow growing, soft, asymptomatic masses. Histopathologically, they appear as thinly encapsulated lesion composed of mature adipocytes with inconspicuous vascularity. The pathogenetic mechanisms of oral lipomas are still unclear. They are usually treated by surgical excision and bear excellent prognosis. Here we report a case of intraoral lipoma in 54 year old male patient in the left lower lingual alveolar mucosal region that was treated by surgical excision using electrocautery without any postsurgical complication. One-year follow-up showed no evidence of recurrence.
\end{abstract}

Key Words: Lipoma, adipocytes, neoplasm, gingiva

\section{INTRODUCTION}

Lipomas are the most common benign mesenchymal tumors surrounded by a thin fibrous capsule. ${ }^{1}$ Oral lipomas represent only $1-4 \%$ of all benign oral soft tissue tumors. The most common intraoral site for lipoma is buccal mucosa and buccal vestibule. Intraoral lipomas show equal predilection for involvement of men and women. Lipoma commonly occur in the $5^{\text {th }}$ or $6^{\text {th }}$ decades of life and are usually asymptomatic until they grow to large size and may interfere with speaking and mastication. ${ }^{2}$ The diagnosis is mainly based on clinical findings with histopathology to rule out other lesions in the same site.

The accepted classification of benign lipomas includes: classic lipoma; lipoma variants (e.g. angiolipoma. chondroid lipoma, myolipoma, spindle cell lipoma); hamartomatous lesions; diffuse lipomatous proliferations; and hibernoma. ${ }^{3}$

The etiology suggested are endocrine, traumatic, and hereditary causes. ${ }^{1}$ The diagnosis is made by pathology of

\section{Correspondence:}

Dr. Sweta Shrestha

Periodontology and Oral Implantology Unit,

Department of Dental Surgery, National Academy of Medical Sciences, Bir Hospital, Kathmandu, Nepal

email: stonasweta@gmail.com

Citation

Shrestha S, Pradhan S, Gorkhali RS. Gingival lipoma: a rare case report. J Nep Soc Perio Oral Implantol. 2017;1:37-9. an incisional or excisional specimen. An important feature is that the tumor tends to float when placed in a $10 \%$ formaldehyde solution. ${ }^{2}$

\section{CASE REPORT}

A 54 year old male patient reported to Department of Dental Surgery, Periodontology and Oral Implantology unit with a chief complaint of painless swelling in the lower left region which interfere with tongue movement and had increased in size for the past 10 years to the present size. No relevant medical history was reported by the patient.

On intraoral examination, solitary, soft, sessile, lobulated mass is seen in the left lingual gingival region extending to alveolar mucosa round in shape, $1.8 \times 1.3 \mathrm{~cm}$ in size located in relation to 33, 34 and 35 . The surface was smooth, nontender, mobile and fluctuant (Figure 1).

Radiographically, (Figure 2) the alveolar bone in the region of the growth appeared normal. Routine hematological

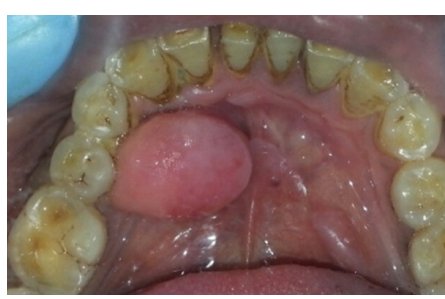

Figure 1: Pre-operative view of mass Figure 2: Intraoral periapical

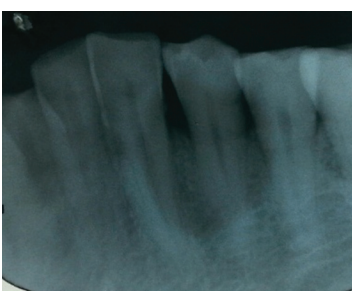

radiographs 


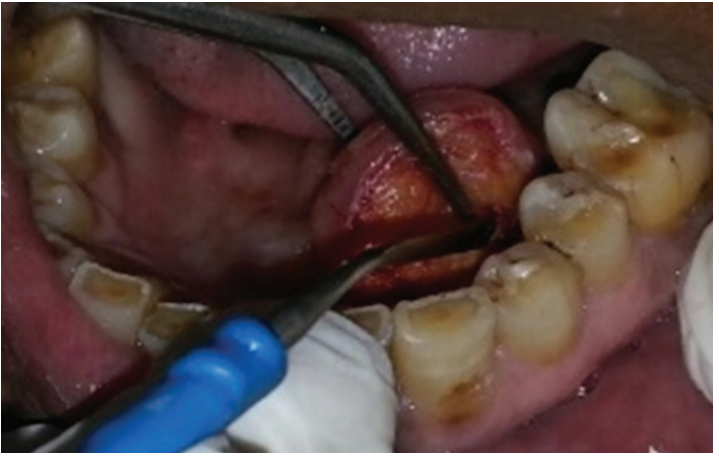

Figure 3: Excision of mass using electrocautery

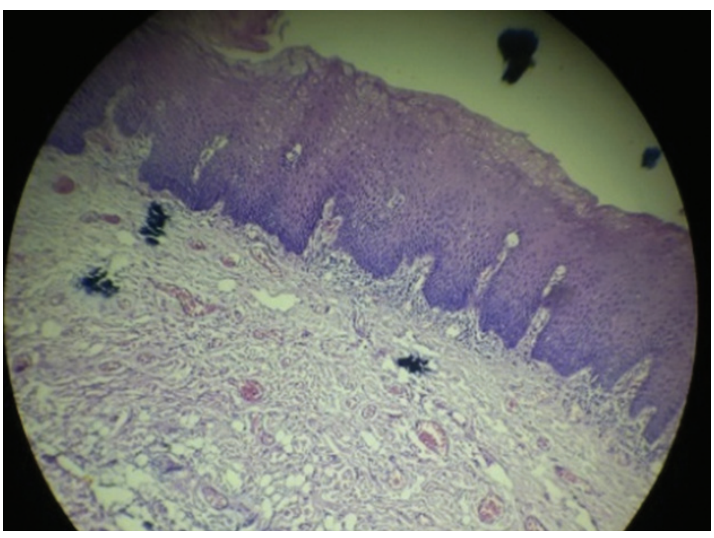

Figure 5: Histopathological section of excised mass

analyses were found to be normal. A provisional diagnosis of lipoma was made. The differential diagnoses were ranulae, epidermoid cysts, pleomorphic adenomas, and fibromas.

After nonsurgical therapy an excisional biopsy was carried out with electrocautery under local anesthesia, followed by curettage (Figure 3). Periodontal dressing was placed and the patient was recalled after 1 week for removal of the pack and checkup. Specimen was placed in $10 \%$ formalin and send for histopathological examination.

Histopathological examination (Figure 5) revealed normal appearing parakeratinized stratified squamous epithelium. The underlying connective tissue reveals numerous benign looking mature adipocytes in the deeper areas with extravasations of RBC at places .A final diagnosis of lipoma was made. The patient is currently being monitored and so far no recurrence has occurred (Figure 4).

\section{DISCUSSION}

Roux in 1848 was the first to describe the intra-oral lipoma, referring it as yellow epulis. ${ }^{4}$ Lipoma is the most common neoplasm arising from fat tissue. However presenting as intraoral masses is an uncommon intraoral finding. ${ }^{1}$

Studart-Soares et al. (2010) investigated the development site in 450 cases of intraoral lipoma reported between 1966
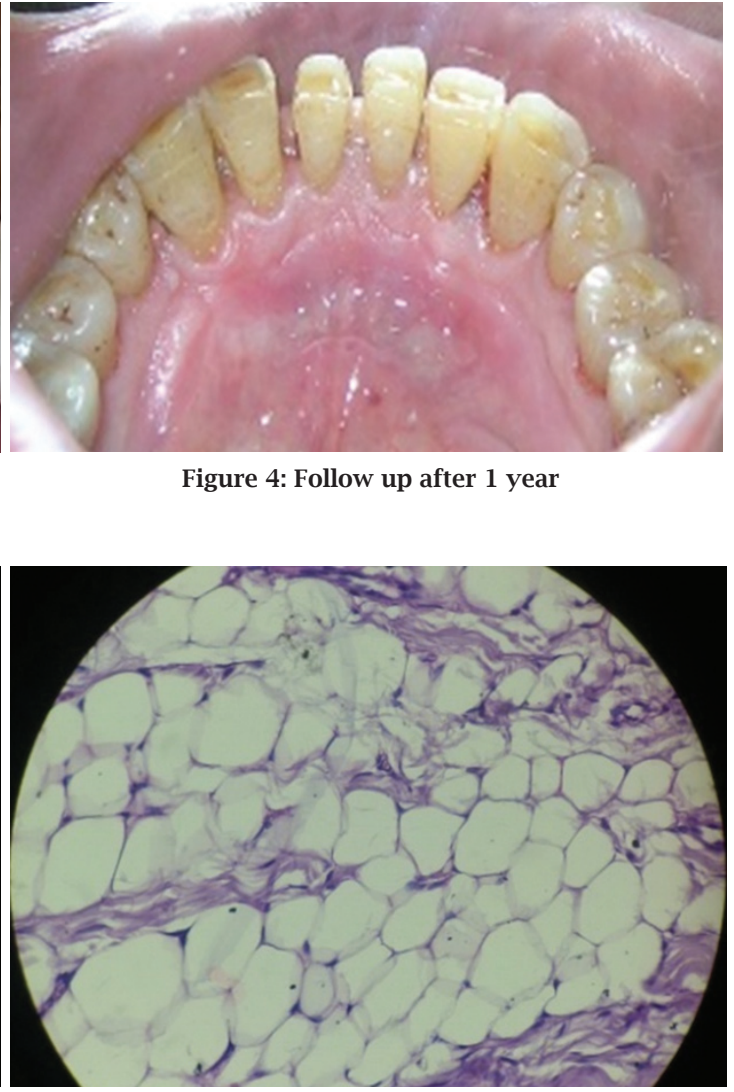

Figure 4: Follow up after 1 year

and 2009, with lesions arising from the buccal mucosa $(\mathrm{n}=174 ; 38.7 \%)$, vestibule $(\mathrm{n}=35 ; 7.8 \%)$, retromolar area $(\mathrm{n}=$ $21 ; 4.7 \%)$, gingiva $(n=4 ; 0.9 \%)$, and others $(n=216 ; 48.0 \%){ }^{5}$

Greer et al. (1973) found that the etiology of the lipoma is obscure. Chronic irritation, trauma, heredity and spontaneous development have been mentioned. Embryonic rests of lipoblasts, fatty degeneration of fibroblasts or metaphase of muscle cells may be responsible for the formation of mature fat cells. ${ }^{7}$

Histologically lipomas consist of mature fat cells arranged into lobules that are separated by septa of fibrous connective tissue. Although morphologically indistinguishable from normal fat, lipomas differ from normal body fat by the fact that their lipid is not available for metabolism and that they are usually surrounded by a thin fibrous capsule. ${ }^{4}$ Sometimes the capsule may be missing or broken. ${ }^{6}$

Bendeca et al. (2007) suggested removal of lipomas because of concerns regarding growth, cosmetic aspects or symptoms resulting from the compression of local structures. In this case mass was surgically removed using electrocautery and no esthetic, functional or neurological abnormalities were observed. The treatment of oral lipomas irrespective of histological variant is simple surgical excision. ${ }^{8}$ 
Shafer et al. (2006) found electrosurgery (ES) has the ability to control bleeding and ensure greater visibility. Other advantages are electrode cuts on its side as well as on its tip, cuts are made with ease when the device is set correctly, the wound is nearly painless and the tip is self disinfecting. However, it has been suggested that ES use results in low tactile sensitivity for cutting, unavoidable burning flesh odor, and poor postoperative healing in the early stages. Using ES, the lateral-heat accumulation should be minimized, and high-speed suction for odor control to facilitate patients' comfort which was effectively accomplished in this case. ${ }^{4}$

Azma et al (2013) studied that diode laser can be used as a modality for oral soft tissue surgery. Excision with laser would reduce bleeding and also lower swelling and scarring of the surgical site, comparing to the simple surgeries. The diode laser can be applied for excision of oral soft tissue. ${ }^{9}$

De Castro et al. (2010) found no recurrence except intramuscular lipomas which has been reported to be 3 to $6.5 \%$. Intramuscular lipomas have a higher recurrence rate because of their infiltrative growth pattern, but this variant is rare in oral and maxillofacial region. ${ }^{10}$

Studarts-Soars et al (2010) found no recurrence in their study series over the 3 years of follow-up. ${ }^{5}$ The present case was followed up for a period of 1 year and no recurrence was observed.

Although rare, malignant transformation of oral lipomas to liposarcomas has been reported. ${ }^{1}$ However Enzinger and Weiss stated that malignant change has never been encountered in a lipoma. ${ }^{11}$

\section{CONCLUSION}

Lipomas are common benign tumours of mature adipocytes however their intraoral occurrence is relatively rare. The histopathologic features should lead to a confirmatory diagnosis of lipoma. Treatment by careful and complete surgical excision is the treatment of choice and recurrence is reported rarely.

\section{REFERENCES}

1. Fregnani ER, Pires FR, Falzoni R, Lopes MA, Vargas PA. Lipomas of the oral cavity: Clinical findings, histological classification and proliferative activity of 46 cases. Int J Oral Maxillofac Surg. 2003;32:49-53.

2. Hoseini AT, Razavi SM, Khabazian A. Lipoma in Oral Mucosa: Two Case Reports. Dent Res J Dent Res J. 2010;7(1):41-43.

3. Fletcher C, Unni K, Mertens F. Adipocytic tumors. World Health Organization classification of tumours: pathology and genetics of tumours of soft tissue and bone. Paul Kleihues MDLHS, MD. editor. IARC Press; IARC Press International Agency for Research on Cancer (IARC) 69008 Lyon, France; 2002.

4. Rajendran R. Shafer's Oral Pathology. 5th ed. Amsterdam: Elsevier; 2006. 194-5 p.

5. Studart-Soares EC, Costa FW, Sousa FB, Alves AP, Osterne RL. Oral lipomas in a Brazilian population: a 10-year study and analysis of 450 cases reported in the literature. Med Oral Patol Oral Cir Bucal. 2010;15(5):691-6.

6. Juliasse LE, Nonaka CF, Pinto LP, Freitas Rde A, Miguel MC. Lipomas of the oral cavity: clinical and histopathologic study of 41 cases in a Brazilian population. Eur Arch Otorhinolaryngol. 2010;267:459-65.

7. Greer RO, Richardson. The nature of lipomas and their significance in the oral cavity. A review and report of cases. Oral Surg Oral Med Oral Pathol. 1973;36(4):551-7.

8. Bandéca MC, de Pádua JM, Nadalin MR, Ozório JE, Silva-Sousa YT, da Cruz Perez DE. Oral soft tissue lipomas: A case series. J Can Dent Assoc. 2007;73:431-4.

9. Azma E, Safavi N. Diode laser application in soft tissue oral surgery. J Lasers Med Sci. 2013;4(4):206-11.

10. De Castro AL, De Castro EV, Felipini RC, Ribeiro AC, Soubhia AM. Osteolipoma of the buccal mucosa. Med Oral Patol Oral Cir Bucal. 2010;15:347-9.

11. Cawson RA, Binnie RH, Speight PM, Bareett AW, Wright JM . - Lucas's Pathology of tumors of the oral tissues: Tumors of adipose tissue. 5th ed: Churchill Livingstone; 1999. 35-69 p. 